\title{
Selection of Controlled Variables for a Natural Gas to Liquids Process
}

\author{
Mehdi Panahi and Sigurd Skogestad* \\ Department of Chemical Engineering, Norwegian University of Science and Technology (NTNU), 7491 Trondheim, Norway
}

ABSTRACT: The aim of this work is to select the best individual or combined controlled variables (CVs) for a natural gas to hydrocarbon liquids (GTL) process based on the idea of self-optimizing control. The objective function is to maximize the variable income of the plant, and two modes of operation are studied. In mode I, where the natural gas flow rate is given, there are three unconstrained degrees of freedom (DOFs) and the corresponding individual self-optimizing CVs are selected as (i) $\mathrm{CO}_{2}$ removal in fresh synthesis gas (syngas), (ii) $\mathrm{CO}$ mole fraction in fresh syngas, and (iii) $\mathrm{CO}$ mole fraction in recycle tail gas from the Fischer-Tropsch (FT) reactor. This set of CVs gives a worst-case loss of 1,393 USD/h. Adding one, two, and three measurements and controlling measurement combinations decrease the worst-case loss significantly, to 184, 161, and 53 USD/h, respectively. In mode II, the natural gas flow rate is a degree of freedom and it is optimal to increase it as much as possible to maximize profit. The variable income increases almost linearly until the oxygen flow rate becomes active. Practically, this is the maximum achievable income. Theoretically, it is possible to increase the natural gas flow rate to improve the objective function, but this results in large recycle flow rates to the FT reactor (similar to "snowballing") because its volume is the limitation.

\section{INTRODUCTION}

For large natural gas reservoirs, converting natural gas to transportable liquid fuels (GTL) is economical when the target markets are further than approximately $2500 \mathrm{~km}$ from the resources. ${ }^{1}$ Figure 1 shows the gas commercialization options and situation of GTL processes compared to other possibilities of transportation, conversion, or usages.

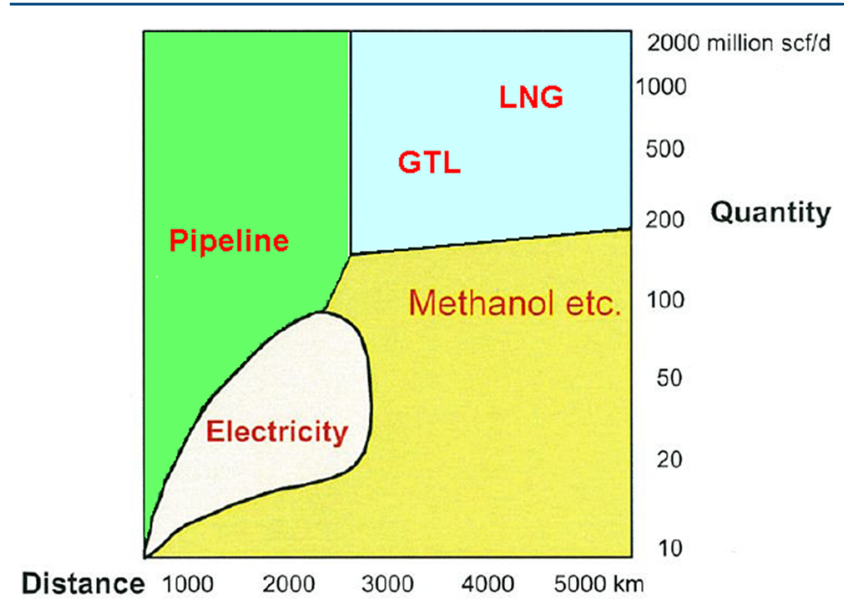

Figure 1. Gas commercialization options and situation of GTL processes. ${ }^{1}$

This paper is an extension of our previous work ${ }^{2}$ which considered modeling and optimization of a GTL process, including degrees of freedom for operation and optimally active constraints. In the present paper, we consider in more detail how to implement operation, using the top-down part of the general plantwide control procedure of Skogestad. ${ }^{3}$ We want to operate the plant economically efficient in the presence of unexpected disturbances. The main issue is, "which variables should be controlled?" To select the best controlled variables, the selfoptimizing method is applied. "Self-optimizing control is when we can achieve an acceptable loss with constant set point values for the controlled variables (CVs) without the need to reoptimize when disturbances occur." 3 This means that we use off-line optimization and analysis to obtain a control structure that can use a constant set point policy for the CVs. This may completely remove the need for a real time optimization layer (RTO) for updating the set points when disturbances occur. However, at least theoretically, we will need to accept a small loss in objective cost compared to the case when RTO is used. By using measurement combinations, the loss can often be decreased significantly and from an engineering point of view close to zero. Based on the loss magnitude, one can decide on using individual or a combination of measurements as self-optimizing CVs.

In general, a different set of self-optimizing variables needs to selected in each operating region (set of active constraints), and in this paper we consider two modes of operation. In mode I, the feed rate to the process is given, and in mode II, the feed rate is adjusted to get the maximum possible profit.

The steps of the self-optimizing method are as follows:

Step 1. Define the objective function and constraints.

Step 2. Identify degrees of freedom (DOFs) for optimization.

Step 3. Identify important disturbances.

Step 4. Optimization for these disturbances.

Step 5. Identify candidate controlled variables (CVs).

Step 6. Select CVs.

In section 3, the self-optimizing steps are followed in detail for the GTL process to select the best controlled variables. The UniSim commercial simulator is used for modeling the process.

Received: November 20, 2011

Revised: May 22, 2012

Accepted: June 20, 2012

Published: June 20, 2012 


\section{PROCESS DESCRIPTION}

GTL processes include three main steps (see Figure 2) to convert natural gas to a range of liquid fuels. In the synthesis gas

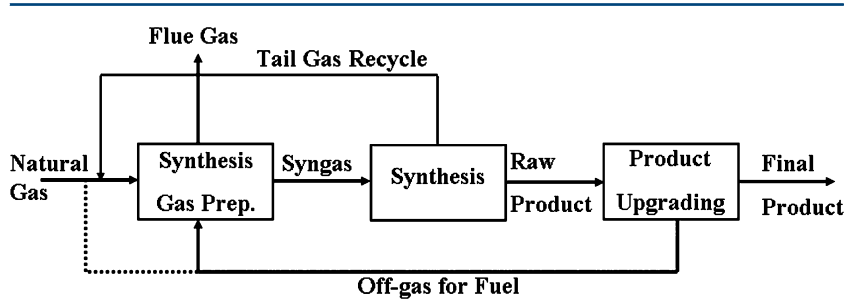

Figure 2. Simple flow sheet of GTL process. ${ }^{4}$

(syngas) unit, natural gas is reacted with oxygen and steam to produce "syngas", a mixture of $\mathrm{CO}$ and $\mathrm{H}_{2}$. This is further converted to a range of liquid hydrocarbon fuels by the highly exothermic Fischer-Tropsch (FT) reactions.

The FT hydrocarbon products include mostly paraffins and olefins, in the range from light (methane) to heavy hydrocarbons (wax). In the final step, the heavier products are upgraded to clean fuels and the lighter hydrocarbons are recycled back to the syngas unit or used as fuel inside the plant.

The GTL flow sheet, process model, and nominal optimal data are taken from our previous work, ${ }^{2}$ where more details are given. The syngas unit is assumed to operate at 30 bar. To simplify, we neglect the pressure drop for the individual equipment in the syngas unit, but we have included a pressure drop between the syngas unit and the FT reactor. ${ }^{5}$ The pressure drop is nominally 3 bar and is simulated using a valve (V-1 in Figure 3 ) with a variable pressure drop as a function of flow rate. Figure 3 shows the process flow sheet with nominally optimal data. The syngas step consists of a pre-reformer, fired heater, and autothermal reformer (ATR), which is claimed to be the best way for syngas production. ${ }^{6}$ The other main units are the $\mathrm{CO}_{2}$ removal for the syngas stream and the FT reactor, which in our case is a cobalt based slurry bubble column reactor (SBCR).

2.1. Fired Heater and Pre-reformer. Fresh natural gas and recycled hydrocarbons from the FT unit are mixed and preheated in the fired heater to $455^{\circ} \mathrm{C}^{5}$ and then enter the pre-reformer. In the pre-reformer, all heavier hydrocarbons are converted by reaction with steam to syngas. The methanation and shift reactions are assumed to be in equilibrium in the pre-reformer. ${ }^{7}$ The advantage of the pre-reformer is that one avoids cracking in the subsequent ATR. The outlet of the pre-reformer is further heated in the fired heater to $675^{\circ} \mathrm{C}$ and then enters the ATR. To control the temperatures of the outlet streams of the fired heater, we use bypass streams (not shown in the flow sheet in Figure 3), which can be viewed as a control degree of freedom. In addition to preheating several streams, the fired heater produces superheated medium pressure (MP) steam which generates electric power for the oxygen plant and for the recycle compressors (compressors I and II in Figure 3).

2.2. Autothermal Reformer. The following reactions take place in the ATR: ${ }^{8}$

oxidation of methane:

$$
\mathrm{CH}_{4}+\frac{3}{2} \mathrm{O}_{2} \leftrightarrow \mathrm{CO}+2 \mathrm{H}_{2} \mathrm{O}
$$

steam reforming of methane:

$$
\mathrm{CH}_{4}+\mathrm{H}_{2} \mathrm{O} \leftrightarrow \mathrm{CO}+3 \mathrm{H}_{2}
$$

shift reaction:

$$
\mathrm{CO}+\mathrm{H}_{2} \mathrm{O} \leftrightarrow \mathrm{CO}_{2}+\mathrm{H}_{2}
$$

In our simulations we assume pure oxygen is supplied from the air separation unit (ASU) although there are some impurities in practice from cryogenic ASU plants. The outlet of the ATR is

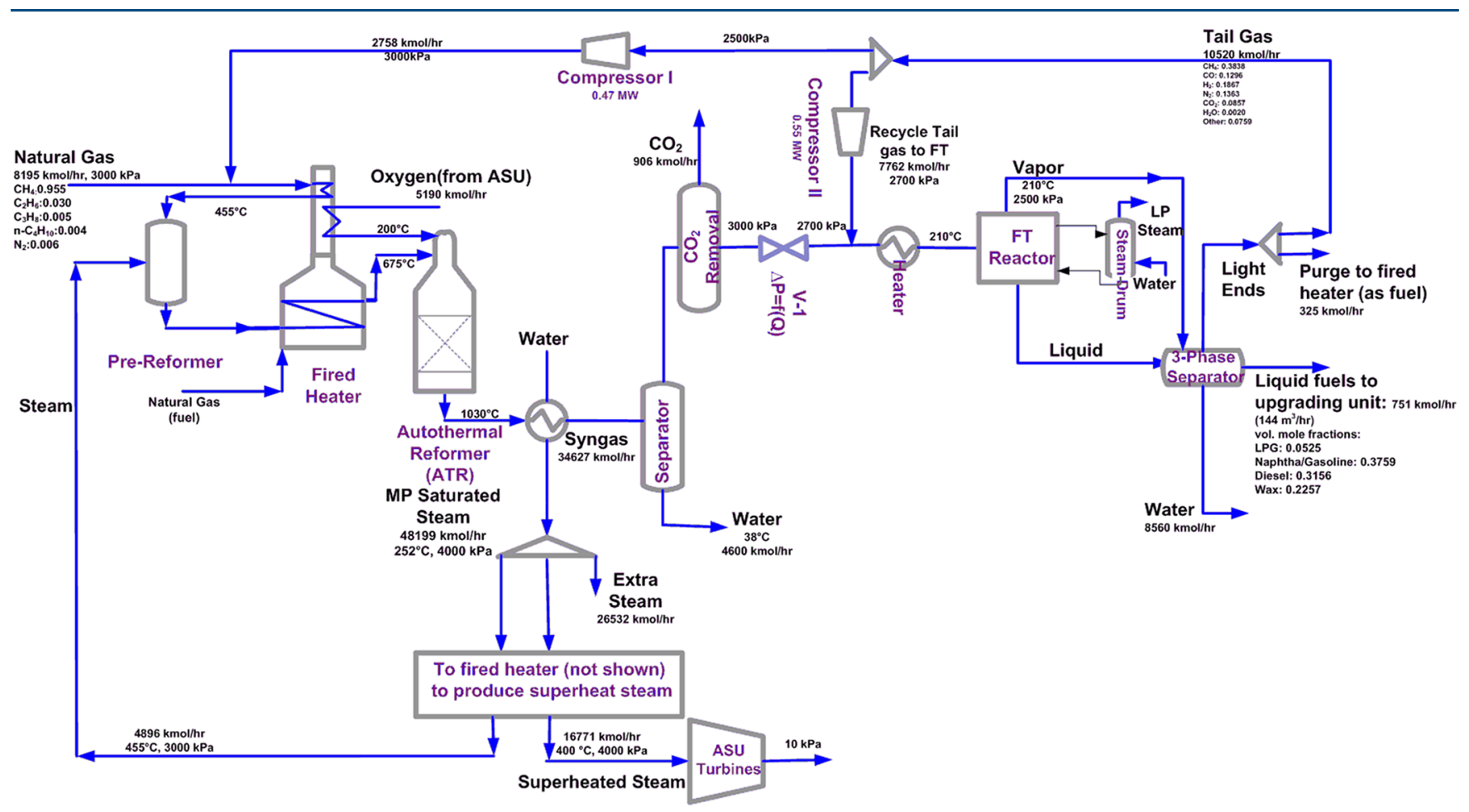

Figure 3. GTL flow sheet with data for optimal nominal point (mode I). 
more than $1000{ }^{\circ} \mathrm{C}$, and the heat is used to generate steam. The syngas is then further cooled to separate out associated water. In the next unit, the $\mathrm{CO}_{2}$ content is reduced. This unit is not modeled in detail, but amine absorption/stripping could be an option. The prepared syngas, which we call the fresh syngas, has a $\mathrm{H}_{2}$ to $\mathrm{CO}$ ratio of around 2 to 2.1 . The exact ratio is decided by optimization.

2.3. Fischer-Tropsch (FT) Reactor. The volume of the FT reactor is assumed to be $2000 \mathrm{~m}^{3}$ with a gas fraction of $40 \%{ }^{5}$ The cooled FT reactor operates at 27 bar and $210{ }^{\circ} \mathrm{C}$ and $U A=$ $19255 \mathrm{~kW} / \mathrm{K}$, where $U$ is the overall heat transfer coefficient and $A$ is the heat transfer area. The FT reactions are highly exothermic, and an advantage of slurry reactors is their excellent heat removal properties. By controlling the boiling water pressure, the reactor temperature can indirectly be controlled. A compressor (compressor II in the flow sheet) was added in the FT recycle loop to compensate for the assumed 2 bar pressure drop in the FT reactor.

The highly exothermic FT reactions are described by Yates and Satterfield reactions. ${ }^{9}$

$$
n \mathrm{CO}+2 n \mathrm{H}_{2} \rightarrow\left(-\mathrm{CH}_{2}-\right)_{n}+n \mathrm{H}_{2} \mathrm{O}
$$

where $n \geq 2$.The products are paraffins and olefins. Methane formation is also unavoidable. We use the proposed reaction rates of Iglesia et al. ${ }^{10}$ for cobalt based FT reactions to simulate the slurry bubble column FT reactor (SBCR).

$$
\begin{aligned}
& r_{\mathrm{CH}_{4}}=\frac{\left(1.08 \times 10^{-8}\right) P_{\mathrm{H}_{2}} P_{\mathrm{CO}}{ }^{0.05}}{1+\left(3.3 \times 10^{-5}\right) P_{\mathrm{CO}}}\left(\frac{\mathrm{mol}_{\mathrm{CH}_{4}}}{\text { g-atom surface metal } \cdot \mathrm{s}}\right) \\
& r_{\mathrm{CO}}=\frac{\left(1.96 \times 10^{-8}\right) P_{\mathrm{H}_{2}}{ }^{0.6} P_{\mathrm{CO}}{ }^{0.65}}{1+\left(3.3 \times 10^{-5}\right) P_{\mathrm{CO}}}\left(\frac{\mathrm{mol}_{\mathrm{CO}}}{\text { g-atom surface metal } \cdot \mathrm{s}}\right)
\end{aligned}
$$

The details of the reaction rates and reactor simulation are given in our previous work. ${ }^{2}$ The following lumps are assumed to describe the FT products: $\mathrm{C}_{1}, \mathrm{C}_{2}$, LPG $\left(\mathrm{C}_{3}-\mathrm{C}_{4}\right)$, gasoline/ naphtha $\left(\mathrm{C}_{5}-\mathrm{C}_{11}\right)$, diesel $\left(\mathrm{C}_{12}-\mathrm{C}_{20}\right)$, and wax $\left(\mathrm{C}_{21+}\right)$. Light ends (mostly $C_{1}$ and $C_{2}$ ) are either recycled to the syngas unit or purged to be used as fuel for the fired heater. The AndersonSchultz-Flory (ASF) model is used to describe the distribution of the products.

$$
w_{n}=n(1-\alpha)^{2} \alpha^{n-1}
$$

Here $w_{n}$ is the weight fraction of hydrocarbons $\left(\mathrm{C}_{n}\right)$ and $\alpha$ is the chain growth probability. Figure 4 illustrates the meaning of chain growth probability.

As Figure 4 shows, the selectivity to hydrocarbons is a function of the chain growth probability. The factor $\alpha$ is a function of the hydrogen to carbon monoxide ratio. In previous work we discussed these dependencies ${ }^{2}$ and showed how significant this ratio is. We use the function proposed by Yermakova and Anikeev ${ }^{11}$ and modified by Song et al. ${ }^{12}$ to calculate chain growth probability:

$$
\alpha=\left(0.2332 \frac{y_{\mathrm{CO}}}{y_{\mathrm{CO}}+y_{\mathrm{H}_{2}}}+0.633\right)[1-0.0039(T-533)]
$$

Here, $y_{\mathrm{CO}}$ and $y_{\mathrm{H}_{2}}$ are mole fractions in the FT reactor and $T$ is the reactor temperature (kelvin).

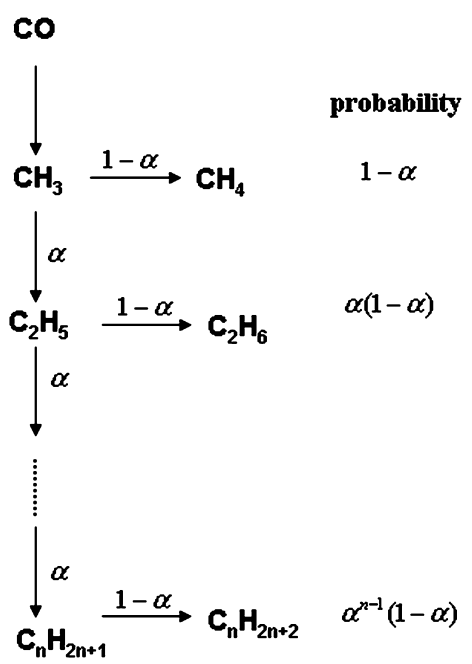

Figure 4. Probability of the chain growth to hydrocarbons in FT reactions. ${ }^{1}$

To summarize the FT reaction loop, note that syngas is converted to a range of hydrocarbons through highly exothermic reactions where the conversion of reactions is dependent on the ratio of $\mathrm{H}_{2}$ to $\mathrm{CO}$, the temperature and pressure of the reactor, the amount, density, and selectivity of the catalyst, the volume of the reactor, and the total mass flow entering the reactor.

In section 3, we apply the self-optimizing method ${ }^{3}$ to select the best individual and combined self-optimizing $\mathrm{CVs}$ for this process.

\section{TOP-DOWN ANALYSIS FOR OPERATION OF THE GTL PROCESS}

We perform the analysis in two modes of operation: in mode I, the natural gas feed flow rate is given (disturbance); in mode II,

Table 1. Assumed Prices for Costs ${ }^{2}$

raw materials:

natural gas: $0.5 \mathrm{USD} / \mathrm{MMBtu}$

water and steam: 0

oxygen: Oxygen is supplied by the ASU unit and we assume that the GTL plant supplies the required steam for the oxygen plant. The price we need to pay decreases somewhat with increased oxygen usage:

$P_{\mathrm{O}_{2}}=P_{\mathrm{O}_{2}}^{\circ}\left(\frac{\dot{m}_{\mathrm{O}_{2}}}{\dot{m}_{\mathrm{O}_{2}}^{\text {ref }}}\right)^{-0.3}, \quad P_{\mathrm{O}_{2}}^{\circ}=0.11 \mathrm{USD} / \mathrm{kg}$

energy: 0 (the required energy is supplied internally by heat integration) $\mathrm{CO}_{2}$ removal: $50 \mathrm{USD} /$ ton of $\mathrm{CO}_{2}$ products:

$$
\begin{aligned}
& \text { LPG }\left(\mathrm{C}_{3}-\mathrm{C}_{4}\right)=0.9 \mathrm{USD} / \mathrm{kg} \\
& \text { gasoline } / \text { naphtha }\left(\mathrm{C}_{5}-\mathrm{C}_{11}\right)=0.73 \mathrm{USD} / \mathrm{kg} \\
& \text { diesel }\left(\mathrm{C}_{12}-\mathrm{C}_{20}\right)=0.71 \mathrm{USD} / \mathrm{kg} \\
& \text { wax }\left(\mathrm{C}_{21+}\right)=0.63 \mathrm{USD} / \mathrm{kg}
\end{aligned}
$$

the natural gas feed flow rate is a degree of freedom for optimization.

3.1. Mode I: Natural Gas Flow Rate Is Given. The steps of the top-down analysis are as follows.

Step 1. Define the Objective Function and Constraints. We define variable income (profit) as the objective function to be maximized.

variable income $=$ sales revenue - variable cost 
Table 2. Optimal Nominal Values

\begin{tabular}{|c|c|c|c|c|c|c|c|c|c|c|c|c|c|}
\hline \multirow[b]{2}{*}{$\mathrm{H}_{2} \mathrm{O} / \mathrm{C}$} & \multirow[b]{2}{*}{$\mathrm{O}_{2} / \mathrm{C}$} & \multirow[b]{2}{*}{$\begin{array}{c}\mathrm{CO}_{2} \\
\text { removal } \\
(\%)\end{array}$} & \multirow[b]{2}{*}{$\begin{array}{l}\text { recycle ratio } \\
\text { to FT }(\%)\end{array}$} & \multirow[b]{2}{*}{$\begin{array}{l}\text { purge of tail } \\
\text { gas (\%) }\end{array}$} & \multirow[b]{2}{*}{$\begin{array}{l}\mathrm{H}_{2} \mathrm{O} / \mathrm{C} \\
\text { fresh }\end{array}$} & \multirow[b]{2}{*}{$\begin{array}{l}\mathrm{H}_{2} \mathrm{O} / \mathrm{C} \\
\text { into FT }\end{array}$} & \multicolumn{2}{|c|}{$\begin{array}{c}\mathrm{CO} \text { conversion } \\
(\%)\end{array}$} & \multicolumn{2}{|c|}{$\begin{array}{c}\mathrm{H}_{2} \text { conversion } \\
(\%)\end{array}$} & \multirow[b]{2}{*}{$\alpha$} & \multirow[b]{2}{*}{$\begin{array}{l}\text { carbon } \\
\text { efficiency } \\
(\%)\end{array}$} & \multirow[b]{2}{*}{$\begin{array}{l}\text { obj function } \\
\text { (USD/h) }\end{array}$} \\
\hline & & & & & & & $\begin{array}{l}\text { per } \\
\text { pass }\end{array}$ & overall & $\begin{array}{l}\text { per } \\
\text { pass }\end{array}$ & overall & & & \\
\hline 0.6010 & 0.5233 & 75.73 & 73.79 & 3 & 2.1 & 2.03 & 85.74 & 95.50 & 89.93 & 96.92 & 0.87 & 74.59 & 49,293 \\
\hline
\end{tabular}

Table 3. Possible Pairings of Steady-State Degrees of Freedom with Equality/Active Controlled Variables

\begin{tabular}{|c|c|}
\hline degree of freedom (DOF) & controlled variable $(\mathrm{CV})$ \\
\hline $\begin{array}{l}\text { 1. superheat steam bypass in fired } \\
\text { heater }\end{array}$ & $\begin{array}{l}\text { superheat steam temperature to pre- } \\
\text { reformer }\end{array}$ \\
\hline $\begin{array}{l}\text { 2. natural gas feed rate as fuel } \\
\text { (makeup) to the fired heater }\end{array}$ & $\begin{array}{l}\text { outlet temperature of fired heater (active } \\
\text { constraint) }\end{array}$ \\
\hline $\begin{array}{l}\text { 3. natural gas }+ \text { recycle hydrocarbon } \\
\text { bypass in fired heater }\end{array}$ & $\begin{array}{l}\text { natural gas }+ \text { recycle hydrocarbon feed } \\
\text { temperature to pre-reformer }\end{array}$ \\
\hline 4. oxygen feed rate to ATR & $\begin{array}{l}\text { ATR outlet temperature (active } \\
\text { constraint) }\end{array}$ \\
\hline 5. oxygen bypass in fired heater & oxygen feed temperature to ATR \\
\hline $\begin{array}{l}\text { 6. cooling duty for water removal } \\
\text { from fresh syngas }\end{array}$ & separator temperature \\
\hline 7. preheater duty for FT reactor & FT reactor inlet temperature \\
\hline $\begin{array}{l}\text { 8. steam (LP) flow rate for FT } \\
\text { reactor cooling }\end{array}$ & steam drum pressure \\
\hline $\begin{array}{l}\text { 9. three-phase separator cooling } \\
\text { duty }\end{array}$ & three-phase separator temperature \\
\hline $\begin{array}{l}\text { 10. compressor II duty (recycle tail } \\
\text { gas flow to FT reactor) }\end{array}$ & compressor II outlet pressure \\
\hline 11. recycle tail gas purge ratio & purge ratio (active constraint) \\
\hline $\begin{array}{l}\text { 12. compressor I duty (recycle tail } \\
\text { gas flow to syngas unit) }\end{array}$ & compressor I outlet pressure \\
\hline
\end{tabular}

Table 4. Five Best Sets of Individual Self-Optimizing CVs in the Optimal Nominal Case (Mode I of Operation)

\begin{tabular}{|c|c|c|c|c|}
\hline \multirow[b]{2}{*}{ no. } & \multicolumn{3}{|c|}{ set } & \multirow{2}{*}{$\begin{array}{c}\text { loss } \\
\text { (USD/ } \\
\mathrm{h})\end{array}$} \\
\hline & & & & \\
\hline 1 & $y_{3}: \mathrm{CO}_{2}$ removal & $\begin{array}{l}y_{9}: \text { CO mole } \\
\text { fraction in fresh } \\
\text { syngas }\end{array}$ & $\begin{array}{l}y_{12}: \mathrm{CO} \text { mole } \\
\text { fraction in tail } \\
\text { gas }\end{array}$ & 1,393 \\
\hline 2 & $y_{3}: \mathrm{CO}_{2}$ removal & $y_{2}: \mathrm{H}_{2} \mathrm{O} / \mathrm{C}$ & $\begin{array}{l}y_{6}: \mathrm{H}_{2} / \mathrm{CO} \text { in tail } \\
\text { gas }\end{array}$ & 1,457 \\
\hline 3 & $y_{3}: \mathrm{CO}_{2}$ removal & $y_{2}: \mathrm{H}_{2} \mathrm{O} / \mathrm{C}$ & $\begin{array}{l}y_{5}: \mathrm{H}_{2} / \mathrm{CO} \text { in } \\
\text { fresh syngas }\end{array}$ & 1,698 \\
\hline 4 & $y_{3}: \mathrm{CO}_{2}$ removal & $\begin{array}{l}y_{6}: \mathrm{H}_{2} / \mathrm{CO} \text { in tail } \\
\text { gas }\end{array}$ & $\begin{array}{l}y_{5}: \mathrm{H}_{2} / \mathrm{CO} \text { in } \\
\text { fresh syngas }\end{array}$ & 2,594 \\
\hline 5 & $\begin{array}{l}y_{10}: \mathrm{CH}_{4} \text { mole } \\
\text { fraction in fresh } \\
\text { syngas }\end{array}$ & $\begin{array}{l}y_{6}: \mathrm{H}_{2} / \mathrm{CO} \text { in tail } \\
\quad \text { gas }\end{array}$ & $\begin{array}{l}y_{5}: \mathrm{H}_{2} / \mathrm{CO} \text { in } \\
\text { fresh syngas }\end{array}$ & 2,643 \\
\hline
\end{tabular}

Table 5. Nonlinear Analysis of the Proposed Self-Optimizing Structure and Corresponding Loss

\begin{tabular}{lc} 
& $\begin{array}{c}\text { loss } \\
\text { (USD/ } \\
\mathrm{h})\end{array}$ \\
$d_{1}: 10 \%$ increase in natural gas feed rate & 88 \\
$d_{2}: 10 \%$ decrease in natural gas hydrocarbon mole fractions (increase & 359 \\
in $\mathrm{N}_{2}$ mole fraction (and corresponding decrease in hydrocarbons) & \\
$d_{3}: 25^{\circ} \mathrm{C}$ decrease in fired heater outlet temperature & 44 \\
\hline
\end{tabular}

variable cost $=$ cost of raw materials + cost of energy

$$
+ \text { cost of } \mathrm{CO}_{2} \text { removal }
$$

The prices for raw materials, products, and other costs are given in Table $1 .^{2}$ Most of the required energy is supplied internally by heat integration or by excess steam; therefore, we did not include the cost for energy. Correspondingly, no credit was assumed for steam generated in the process (MP steam in boiler after ATR, low pressure (LP) steam in FT reactor). We expect that this assumption will not affect our control structures. For the $\mathrm{CO}_{2}$ removal unit costs, in the presence of extra steam in the plant, the required energy for regenerating of solvent can be easily supplied. Anyway, we have included $50 \mathrm{USD} /$ ton $\mathrm{CO}_{2}$ in the optimization.

The inequality constraints are as follows.

1. The feed syngas molar ratio $\mathrm{H}_{2} \mathrm{O} / \mathrm{C} \geq 0.3$ to ensure sootfree conditions. Carbon in this ratio includes fresh and recycled hydrocarbons. Note that Holdor Topsøe reports soot free operations at even lower values, ${ }^{6}$ but we choose 0.3 as the lower bound.

2. The inlet temperature of the ATR (outlet of fired heater) $\leq 675{ }^{\circ} \mathrm{C}$. The reason for this limit is piping material constraint. $^{13}$

3. The outlet of ATR $\leq 1030{ }^{\circ} \mathrm{C}$. This temperature is an average of several ATR temperatures reported by Holdor Topsøe ${ }^{14}$ which ensures soot-free operation.

4. To avoid a convergence problem, for simulation purposes, the purge ratio of tail gas is bounded at $3 \%$ although the optimal is a lower value at around $2 \%$. The purpose of the purge stream is to get rid of the nitrogen entering the fresh natural gas feed.

5. In addition, there are capacity constraints on the variable units: fired heater (duty $+40 \%$ compared to nominal), $\mathrm{CO}_{2}$ removal unit $(+20 \%$ feed rate), and oxygen plant ( $+20 \%$ oxygen flow rate).

The equality constraints, most of which were explained in the process description, are the following:

1. The fresh natural gas + recycle hydrocarbon temperature to the pre-reformer is kept at $455{ }^{\circ} \mathrm{C}$.

2. The steam temperature to the pre-reformer is kept at 455 ${ }^{\circ} \mathrm{C}$.

3. The oxygen feed temperature to the ATR is kept at 200 ${ }^{\circ} \mathrm{C}$.

4. The feed enters the syngas unit at 30 bar. Note that the pressure of the fresh streams are set in other units which are outside our flow sheet boundary.

5. The fresh syngas from the ATR (after passing the boiler) is cooled to $38{ }^{\circ} \mathrm{C}$ for separation of water content.

6. The syngas enters into the FT reactor at $210^{\circ} \mathrm{C}$.

7. The boiling water pressure (cooling medium of the FT reactor) is kept at 12.5 bar (low pressure (LP) steam) to indirectly control the FT reactor temperature. This gives a gradient of $20{ }^{\circ} \mathrm{C}$ between the FT desired temperature $\left(210^{\circ} \mathrm{C}\right)$ and the coolant $\left(190^{\circ} \mathrm{C}\right)$.

8. FT products are cooled to $30^{\circ} \mathrm{C}$ in a three-phase separator to separate liquid fuels, water, and tail gas.

9. The recycle tail gas to FT reactor is compressed to 27 bar. 


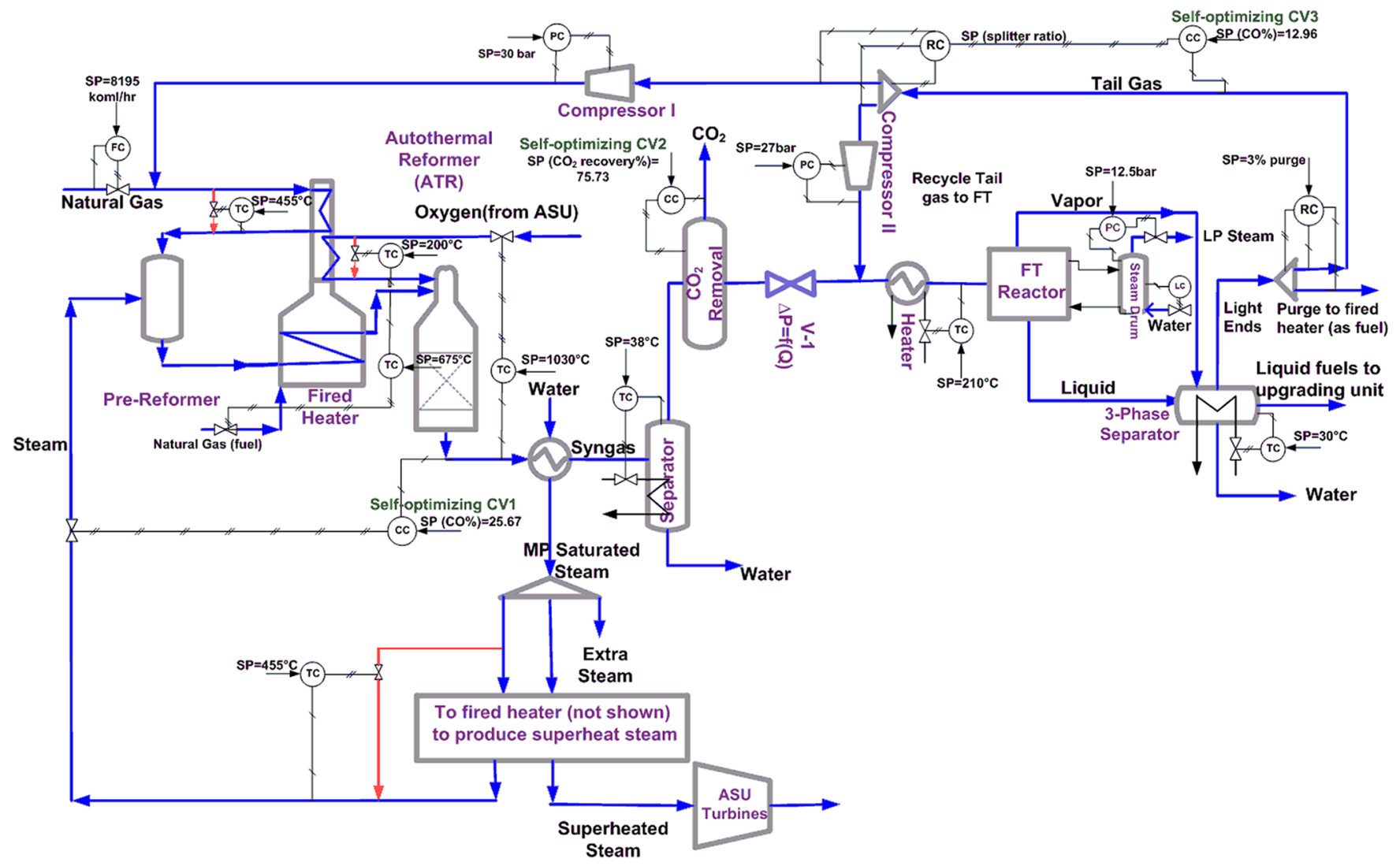

Figure 5. Possible control structure for the steady-state degrees of freedom for mode I of operation. (Red lines are bypass streams.) Note that we are considering the selection of steady-state CVs, so we are not concerned with inventory control. The inventory loops on the flow sheet, including pressure control, are included for steady-state simulation purposes and do not necessarily correspond to the actual loops. For example, in practice, the pressure in the FT reactor may be controlled using the purge flow, and the purge two split ratios should be controlled using compressors I and II. Also, the actual valve for controlling the split would be on the purge flow because we do not want any valves in the gas recycle, but again it would give the same result at steady state.

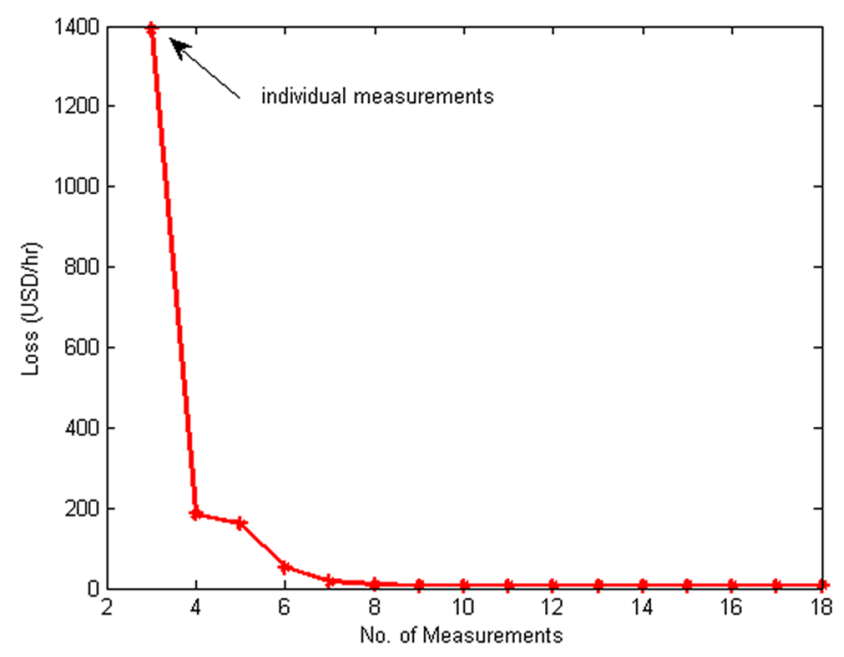

Figure 6. Minimum worst-case loss with different numbers of measurements (mode I).

Step 2. Identify Degrees of Freedom (DOFs) for Optimization. There are 15 main steady-state operational degrees of freedom which can be selected (the reader is referred to our previous work ${ }^{2}$ for a detailed discussion):

1. $\mathrm{H}_{2} \mathrm{O}$ (superheat steam) feed rate to pre-reformer (this can be viewed also as the ratio $\mathrm{H}_{2} \mathrm{O} / \mathrm{C}$ )

2. superheat steam bypass in fired heater
3. natural gas feed rate as fuel (makeup) to the fired heater

4. natural gas + recycle hydrocarbon bypass in fired heater

5. oxygen feed rate to ATR

6. oxygen bypass in fired heater

7. cooling duty for water removal from fresh syngas

8. $\mathrm{CO}_{2}$ removal

9. preheater duty for FT reactor

10. steam (LP) flow rate for cooling FT reactor

11. three-phase separator cooling duty for separation of FT products

12. recycle ratio to FT reactor, which is the percentage of recycled tail gas that enters the FT reactor (The rest is recycled back to the syngas unit (pre-reformer).)

13. compressor II duty (recycle tail gas flow to FT reactor)

14. recycle tail gas purge ratio

15. compressor I duty (recycle tail gas flow to syngas unit)

Step 3. Identification of Important Disturbances. The main disturbances $(d)$ from an industrial point of view are variations in the natural gas feed rate, natural gas composition, and natural gas price. We also include a variation in the FT "kinetic parameter" to include the effect of model mismatch in FT reactions in our analysis. In addition, the value of all active constraints may be considered as disturbances (see the optimization part further for final selection of the active constraints). We determine the maximum expected value for each disturbance in step 6 .

Step 4. Optimization. We first did the optimization for the nominal case using the "Mixed method" in UniSim. This method 
Table 6. Optimal Measurement Combinations (CVs) with Corresponding Losses (Mode I)

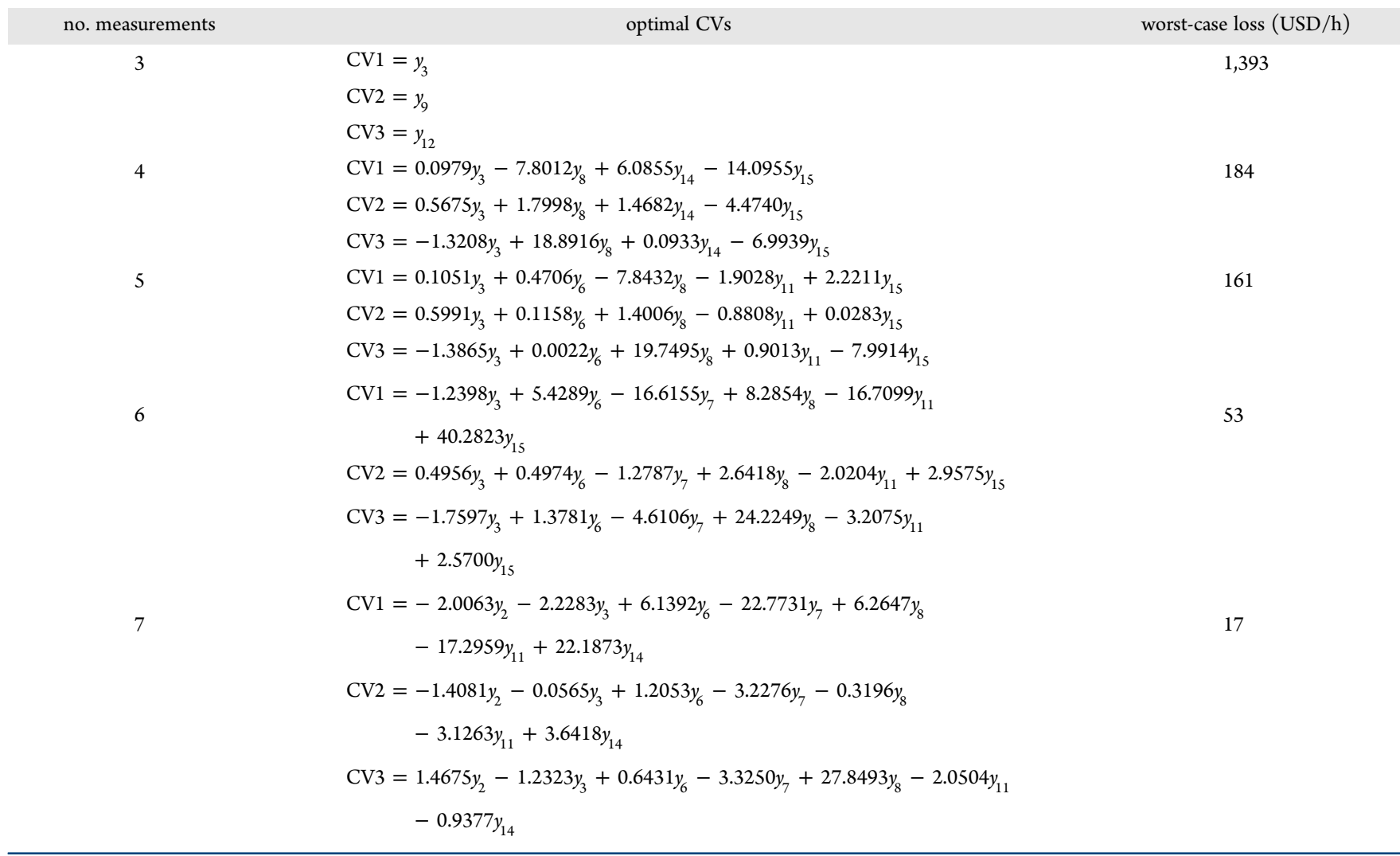

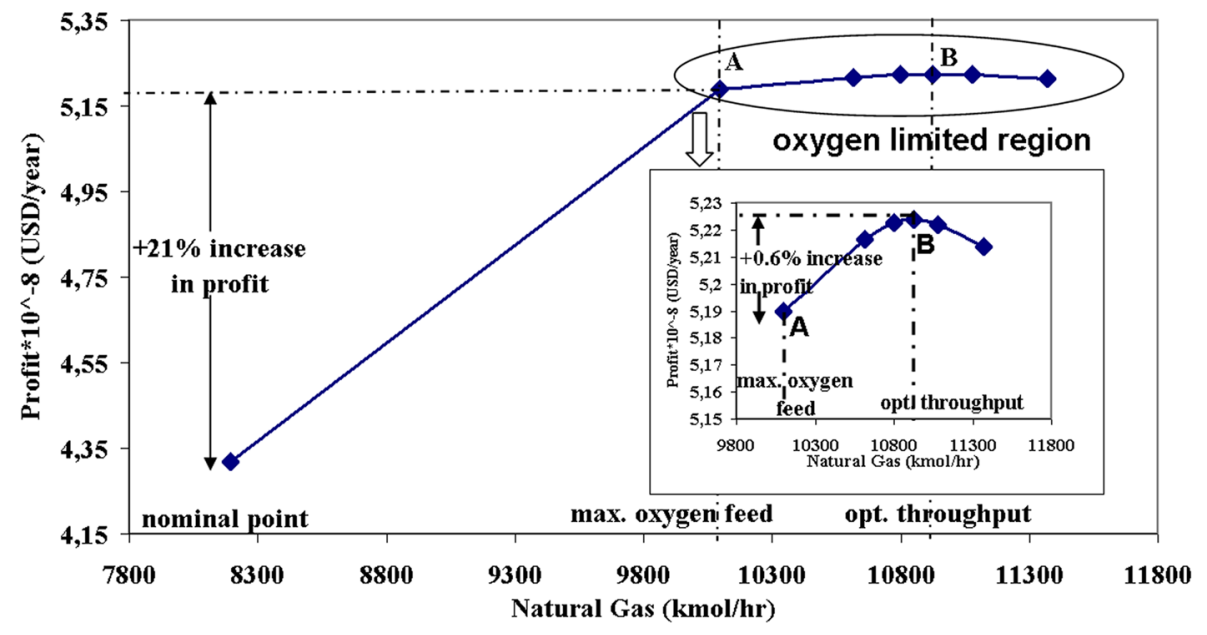

Figure 7. Optimal profit as a function of natural gas flow rate. Point A; near maximum profit (recommended operating point); point B, maximum achievable profit (optimal throughput).

tries to combine the advantage of global optimization of the BOX method and the efficiency of the SQP method. Initially, it uses the BOX method with a very loose convergence tolerance and then switches to the SQP method to locate the final solution with the desired tolerance. ${ }^{15}$ Figure 3 shows the optimal nominal flow sheet. Table 2 shows the optimal nominal values of some of the important parameters. The "carbon efficiency" in Table 2 is the ratio of the carbon in the produced hydrocarbons to the carbon in the feed natural gas, including the required natural gas as fuel in the fired heater.

We find three active constraints during optimal nominal operation:
1. The outlet temperature of the fired heater is active at the maximum $\left(675^{\circ} \mathrm{C}\right)$.

2. The outlet temperature of the ATR is active at the maximum $\left(1030^{\circ} \mathrm{C}\right)$.

3. The purge ratio is active at the specified minimum, which is to purge $3 \%$ of the tail gas.

Since change at any of these active constraints has a significant effect on the objective function value, ${ }^{2}$ we included all of them as disturbances during analysis.

We have 15 steady-state degrees of freedom, 9 equality constraints, and 3 active constraints, which each needs one degree of freedom for control. Therefore, we have 3 (=15-93) remaining unconstrained degrees of freedom. 


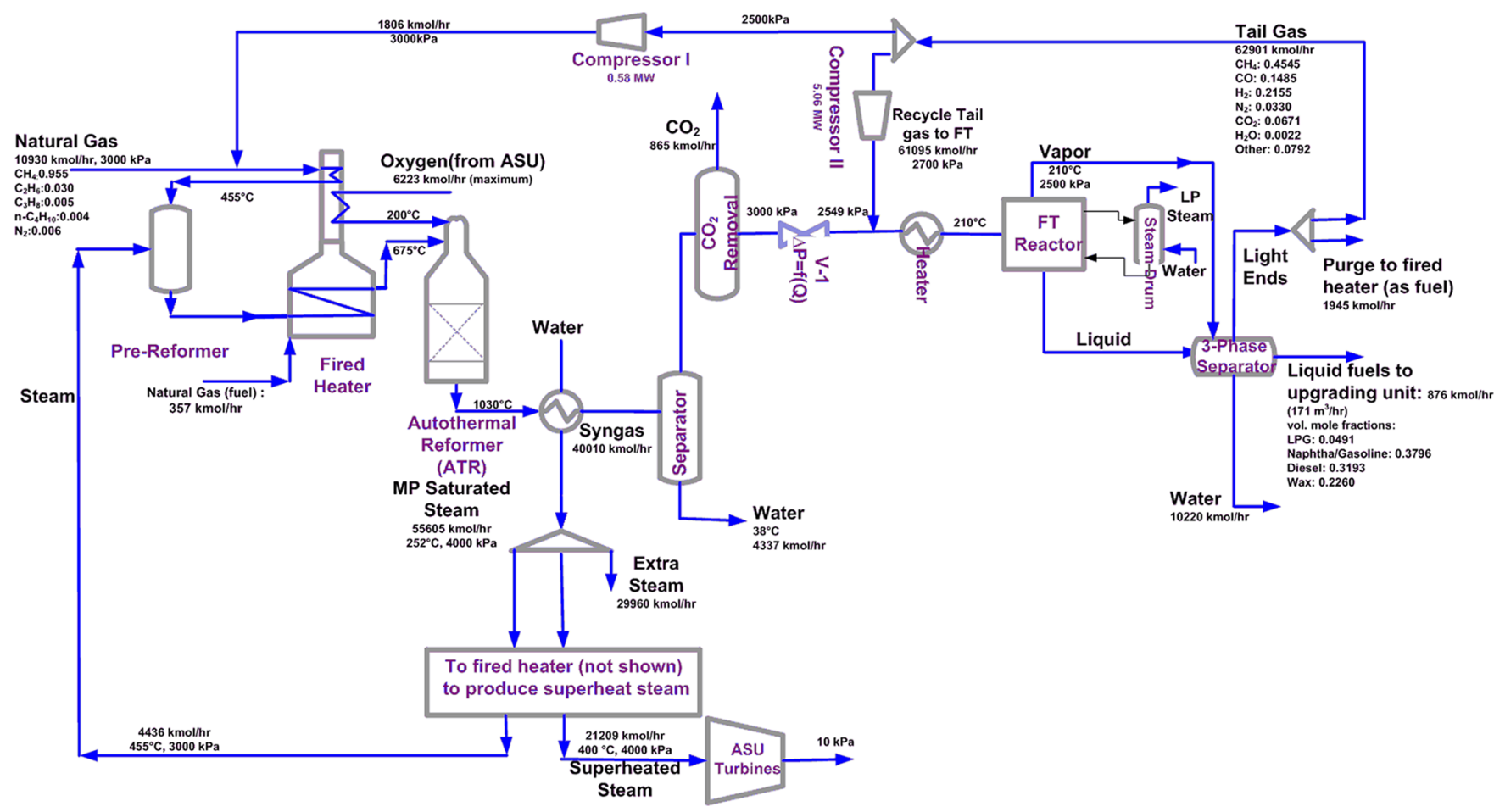

Figure 8. GTL flow sheet with data for optimal throughput (mode II, point B).

Unconstrained CVs in Mode I. There are many ways to pair the constraints with the degrees of freedom (inputs), but with the suggested pairings in Table 3, we are left with the following unconstrained degrees of freedom: $u_{1}$, the feed $\mathrm{H}_{2} \mathrm{O} / \mathrm{C} ; u_{2}$, the $\mathrm{CO}_{2}$ removal percent before the FT reactor; and $u_{3}$, the recycle ratio to the FT reactor.

The objective is now to select the best three self-optimizing CVs to pair with these DOFs. Note that the actual choice of unconstrained degrees of freedom $\left(u_{1}, u_{2}, u_{3}\right)$ does not really matter and we would have obtained equivalent results with other choices, although the matrices $G^{y}, G_{d}^{y}, J_{u w}$ and $F$ in the subsequent analysis would be different.

Step 5. Identification of Candidate Controlled Variables. We consider 18 candidate measurements including the three unconstrained degrees of freedom (actually, all 15 DOFs could have been considered, but we only consider these three):

1. $\mathrm{O}_{2} / \mathrm{C}\left(y_{1}\right)$

2. feed $\mathrm{H}_{2} \mathrm{O} / \mathrm{C}=u_{1}\left(y_{2}\right)$

3. $\mathrm{CO}_{2}$ removal $\%=u_{2}\left(y_{3}\right)$

4. recycled tail gas ratio to FT reactor $=u_{3}\left(y_{4}\right)$

5. $\mathrm{H}_{2} / \mathrm{CO}$ in fresh syngas $\left(y_{5}\right)$

6. $\mathrm{H}_{2} / \mathrm{CO}$ in tail gas $\left(y_{6}\right)$

7. $\mathrm{H}_{2} / \mathrm{CO}$ into FT reactor $\left(y_{7}\right)$

8. $\mathrm{H}_{2}$ mole fraction in fresh syngas $\left(y_{8}\right)$

9. CO mole fraction in fresh syngas $\left(y_{9}\right)$

10. $\mathrm{CH}_{4}$ mole fraction in fresh syngas $\left(y_{10}\right)$

11. $\mathrm{H}_{2}$ mole fraction in tail gas $\left(y_{11}\right)$

12. CO mole fraction in tail gas $\left(y_{12}\right)$

13. $\mathrm{CH}_{4}$ mole fraction in tail gas $\left(y_{13}\right)$

14. $\mathrm{H}_{2}$ mole fraction into $\mathrm{FT}$ reactor $\left(y_{14}\right)$

15. CO mole fraction into FT reactor $\left(y_{15}\right)$

16. fresh syngas flow rate $\left(y_{16}\right)$

17. tail gas flow rate to syngas unit $\left(y_{17}\right)$

18. tail gas flow rate to FT reactor $\left(y_{18}\right)$
This is not a complete list, but it includes some of the most obvious and practical candidates to measure and control. We have 18 candidate measurements, and one needs to select three individual measurements, $\mathrm{CV}=H y$, where $H$ is the selection matrix. Therefore there are

$$
\left(\begin{array}{l}
18 \\
3
\end{array}\right)=\frac{18 !}{3 ! 15 !}=816
$$

possible single measurement candidate sets. The self-optimizing method is applied in the next step to choose the best set.

Step 6. Selection of CVs. To find the best set of CVs, we applied the "exact local method", ${ }^{16}$ which gives the maximum loss imposed by each candidate set in the presence of disturbances and measurement noise. The set with the minimum worst-case loss is the best. Expressions $12-15$ give the mathematical formulation of calculating loss.

$$
\begin{aligned}
& \text { worst-case loss }=\frac{1}{2} \bar{\sigma}(M)^{2} \\
& M=J_{u u}^{1 / 2}\left(H G^{y}\right)^{-1}\left(H\left[\begin{array}{ll}
F W_{d} & W_{n}
\end{array}\right]\right)
\end{aligned}
$$

where the optimal sensitivity $(F)$ can be obtained analytically from (14) or numerically by reoptimizing the process from (15).

$$
\begin{aligned}
& F=G^{y} J_{u u}^{-1} J_{u d}-G_{d}^{y} \\
& F=\frac{\Delta y^{\mathrm{opt}}}{\Delta d}
\end{aligned}
$$

In (12), $\bar{\sigma}(M)$ is the maximum singular value of matrix $M, J_{u u}$ is the Hessian of the objective function with respect to unconstrained DOFs, $G^{y}$ is the gain of the selected measurements from the inputs, $W_{d}$ is the expected magnitude of the disturbances, $W_{n}$ is the implementation error, $J_{u d}$ is the second derivative of the objective function with respect to DOFs and disturbances, and $G_{d}^{y}$ is the gain from disturbances to the selected measurements. It 


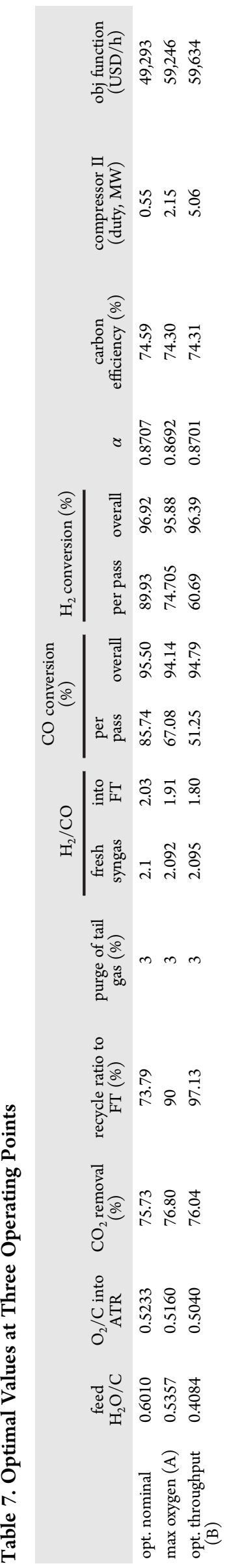

is worth knowing that the Frobenius norm, which gives the average loss, could be used instead of worst-case loss, but both methods give the same results. ${ }^{17}$

We consider seven disturbances (d) with the following maximum expected magnitude (included in the diagonal matrix, $\left.W_{d}\right):$

$d_{1}$ (natural gas (NG) flow rate): $10 \%$

$d_{2}$ (NG hydrocarbon composition): $10 \%$; the disturbance $d_{2}$ is an increase in $\mathrm{N}_{2}$ mole fraction (and corresponding decrease in hydrocarbons) (In the analysis it was set at $10 \%\left(W_{d}\right)$, but in the simulation we only used $3 \%$.)

$d_{3}$ (fired heater outlet temperature): $30{ }^{\circ} \mathrm{C}$

$d_{4}$ (ATR outlet temperature): $40{ }^{\circ} \mathrm{C}$

$d_{5}$ (FT reaction rate constant): $10 \%$

$d_{6}$ (purge ratio): $15 \%$

$d_{7}$ (NG price): $10 \%$

The implementation error (measurement noise) for the candidate measurements is assumed to be (included in the diagonal matrix, $W_{n}$ ) the following: compositions, $0.1 \%$, flow rates, $10 \%$, split ratios, $15 \%$.

Individual Measurements as CVs. A branch and bound algorithm $^{18}$ is applied to find the best set of single measurements with the minimum worst-case loss. Table 4 shows the five best sets with their corresponding worst-case losses. The smallest loss is obtained by controlling the $\mathrm{CO}_{2}$ removal $\left(y_{3}\right)$ in the $\mathrm{CO}_{2}$ removal unit, the $\mathrm{CO}$ mole fraction in the fresh syngas $\left(y_{9}\right)$, and the CO mole fraction in the tail gas $\left(y_{12}\right)$.

We pair the CVs of the best set with the corresponding closeby manipulated variables: $\mathrm{CV} 1=\mathrm{CO}$ mole fraction in outlet of the $\operatorname{ATR}\left(y_{9}\right)$ is controlled using $u_{1}=$ feed $\mathrm{H}_{2} \mathrm{O} / \mathrm{C} . \mathrm{CV} 2=\mathrm{CO}_{2}$ removal \% $\left(y_{3}\right)$ is controlled using $u_{2}=\mathrm{CO}_{2}$ removal plant. CV3 $=\mathrm{CO}$ mole fraction in tail gas $\left(y_{12}\right)$ is controlled using $u_{3}=$ recycle tail gas ratio to the FT reactor. The resulting control structure is shown in Figure 5. The CV2 "pairing" seems strange, but it follows because we have not modeled in detail the $\mathrm{CO}_{2}$ unit, so the input $\left(u_{2}\right)$ is actually a $\mathrm{CV}\left(y_{3}\right)$. The demonstrated control loop just determines that the $\mathrm{CO}_{2}$ removal percentage is controlled internally by the $\mathrm{CO}_{2}$ removal plant. Manipulating of recycle amine in case an amine absorption/stripping system is applied will be one possibility for controlling the $\mathrm{CO}_{2}$ removal.

The self-optimizing method is based on a linear analysis; therefore, a nonlinear analysis for selected CVs is required. The three self-optimizing CVs are kept constant in their optimal nominal points using the suggested pairings in the flow sheet and then the disturbances $d_{1}, d_{2}$, and $d_{3}$ are implemented as mentioned in Table 5. In addition, the flow sheet is reoptimized for each disturbance to find the corresponding economic loss. In all cases the flow sheet converges without reaching a new constraint. Similar conclusions from other disturbances are expected. Loss values are also all smaller than the maximum worst-case loss $(1,393 \mathrm{USD} / \mathrm{h})$ given by the analysis.

Measurement Combinations as CVs. As the loss of the best individual sets of measurements in Table 4 is fairly high (compared to the objective function value in the optimal nominal point), we consider measurement combinations as $\mathrm{CVs}, \mathrm{CV}=$ $H y$, where $H$ is a "full matrix" in terms of the selected measurements, to get a smaller loss. ${ }^{19}$ The optimal $H$ is obtained by solving the following optimization problem.

$$
\begin{aligned}
& \min _{H}\|H Y\|_{\mathrm{F}}^{2} \\
& \text { s.t. } \quad H G^{y}=J_{u u}{ }^{1 / 2}
\end{aligned}
$$




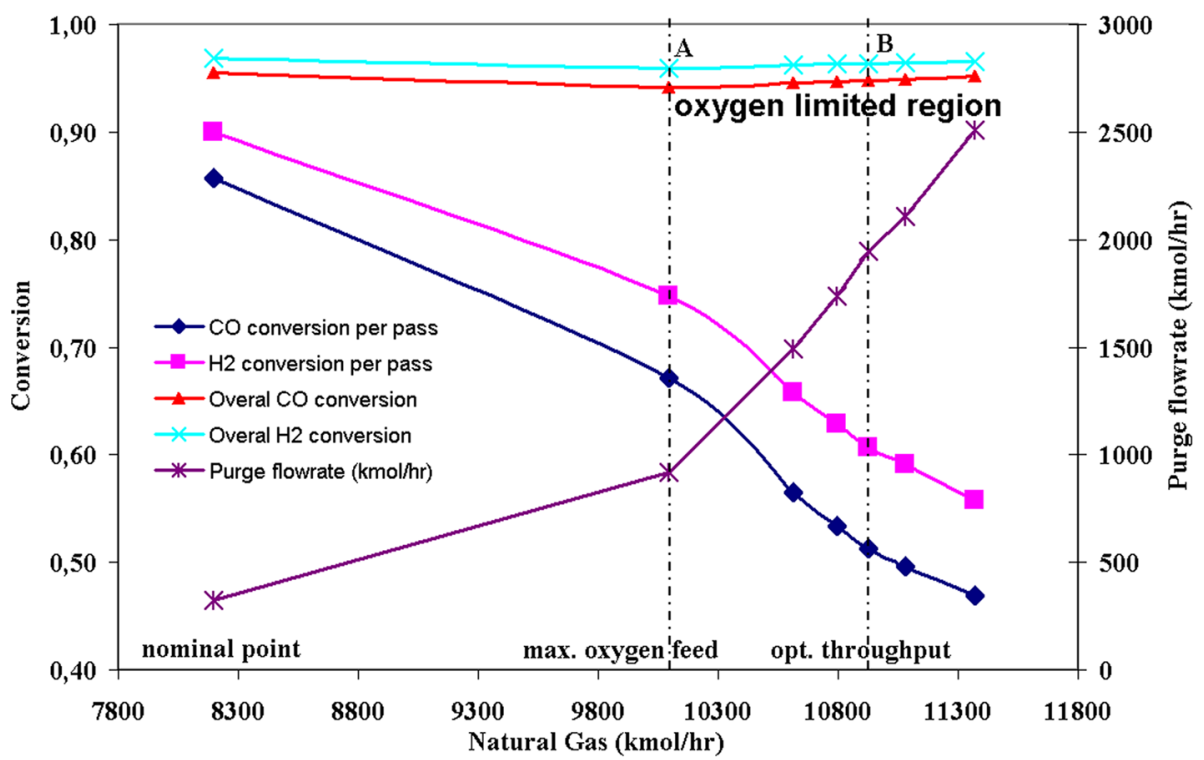

Figure 9. Optimal values of $\mathrm{CO}$ and $\mathrm{H}_{2}$ conversion (single pass and overall) in FT reactor and purge flow rate as function of natural gas feed rate.

Table 8. Five Best Sets of Individual Self-Optimizing CVs in the Optimal Throughput Case (Mode II, Point B)

\begin{tabular}{|c|c|c|c|c|}
\hline \multirow[b]{2}{*}{ no. } & \multicolumn{3}{|c|}{ set } & \multirow{2}{*}{$\begin{array}{c}\text { loss } \\
\text { (USD/ } \\
\mathrm{h})\end{array}$} \\
\hline & & & & \\
\hline 1 & $\begin{array}{l}y_{3}: \mathrm{CO}_{2} \\
\text { removal }\end{array}$ & $y_{2}: \mathrm{H}_{2} \mathrm{O} / \mathrm{C}$ & $\begin{array}{l}y_{7}: \mathrm{H}_{2} / \mathrm{CO} \text { into } \mathrm{FT} \\
\text { reactor }\end{array}$ & 3,022 \\
\hline 2 & $\begin{array}{l}y_{3}: \mathrm{CO}_{2} \\
\text { removal }\end{array}$ & $y_{2}: \mathrm{H}_{2} \mathrm{O} / \mathrm{C}$ & $y_{6}: \mathrm{H}_{2} / \mathrm{CO}$ in tail gas & 3,316 \\
\hline 3 & $\begin{array}{l}y_{3}: \mathrm{CO}_{2} \\
\text { removal }\end{array}$ & $y_{2}: \mathrm{H}_{2} \mathrm{O} / \mathrm{C}$ & $\begin{array}{l}y_{5}: \mathrm{H}_{2} / \mathrm{CO} \text { in fresh } \\
\text { syngas }\end{array}$ & 3,495 \\
\hline 4 & $\begin{array}{l}y_{3}: \mathrm{CO}_{2} \\
\text { removal }\end{array}$ & $y_{2}: \mathrm{H}_{2} \mathrm{O} / \mathrm{C}$ & $\begin{array}{l}y_{17}: \text { tail gas flow rate to } \\
\text { syngas unit }\end{array}$ & 4,179 \\
\hline 5 & $\begin{array}{l}y_{3}: \mathrm{CO}_{2} \\
\text { removal }\end{array}$ & $\begin{array}{l}y_{9}: \text { CO mole fraction } \\
\text { in fresh syngas }\end{array}$ & $\begin{array}{l}y_{15}: \text { CO mole fraction } \\
\text { into FT reactor }\end{array}$ & 4,419 \\
\hline
\end{tabular}

where $Y=\left[\begin{array}{ll}F W_{d} & W_{n}\end{array}\right]$. An analytical solution ${ }^{19}$ for $(16)$ is

$$
H^{\mathrm{T}}=\left(Y Y^{\mathrm{T}}\right)^{-1} G^{y}\left(G^{y \mathrm{~T}}\left(Y Y^{\mathrm{T}}\right)^{-1} G^{y}\right)^{-1} J_{u u}^{1 / 2}
$$

A partial branch and bound algorithm ${ }^{20}$ is applied to find the best set of CVs with more measurements than three. Figure 6 and Table 6 show the results of solving (12) and (16) for different numbers of measurements.

The results show that by having four measurements the loss decreases significantly from 1,393 to $184 \mathrm{USD} / \mathrm{h}$ and by having five and six measurements the loss decreases further to 161 and $53 \mathrm{USD} / \mathrm{h}$, respectively. By combining seven measurements the best worst-case loss is $17 \mathrm{USD} / \mathrm{h}$, which is almost 0 from a practical point of view. Measurement $y_{3}\left(\mathrm{CO}_{2}\right.$ removal $)$ is always included, but the other measurements in the optimal set vary. One disadvantage of measurement combinations is the lack of physical meaning. Also, dynamic issues, such as inverse response, may cause problems for control, and it may be necessary to use cascade control. It is recommended to perform dynamic simulations to test the practicality of the selected combined CVs.

3.2. Mode II: Natural Gas Feed Is a Degree of Freedom for Optimization. From an economical point of view with the given prices, it is optimal to increase the amount of natural gas feed as much as possible to get more profit. As mentioned earlier, the following maximum capacity constraints are included:
- duty of fired heater: $+40 \%$ compared to nominal in mode I

- feed rate to $\mathrm{CO}_{2}$ removal unit: $+20 \%$

- oxygen feed rate: $+20 \%$

We did not include any upper bound on the compressor duties. This is because in mode I the nominal compressor duties (compressor I, $0.47 \mathrm{MW}$; compressor II, $0.55 \mathrm{MW}$ ) are small compared with the duty of the fired heater (energy duty, 328.6 $\mathrm{MW}$ ), so we may consider basing the design capacity for the compressors on the mode II operation.

The profit is shown as a function of the feed rate in Figure 7. In addition to the oxygen flow rate, the outlet temperature of the fired heater (at maximum), the outlet temperature of the ATR (at maximum), and the purge ratio (at minimum) are also active; they are the same active constraints as in the nominal case. The profit increases almost linearly with the natural gas flow rate (see Figure 7) up to the point when the first capacity constraint is reached, which is when the oxygen flow rate reaches its maximum (point A in Figure 7). At this point the increase in natural gas feed rate is $+23.18 \%$ (compared to the nominal point). The reason it does not increase completely linearly is because of the fixed volume of the FT reactor, which implies that the optimal values of the intensive variables change somewhat.

The feed rate can be increased further to $+33.32 \%$ (point $B$ in Figure 7 ), at which we reach the bottleneck where a further increase gives infeasible operation. Figure 8 shows the optimal flow sheet at the optimal throughput. Table 7 summarizes the optimal values of the main parameters. However, note from Figure 7 and Table 7 that although the profit increases by $+21.0 \%$ from the nominal point to point $A$, it only has a very small further increase to $+21.6 \%$ in point $B$. Thus, in practice, operating point A may actually be the optimal, because in point $B$ the compressor work is about twice as large as in point $\mathrm{A}$. The compressor work is included in our economic optimization, but the minor operational economic benefit in point $\mathrm{B}$ may not justify the extra capital costs of a larger compressor. Also, there are other operational disadvantages with large variations in the recycle flow ("snowballing") and there is also the issue of less effective use of resources in point B since the purge flow is large. Nevertheless, we choose to work with operating point B for the further control studies. 


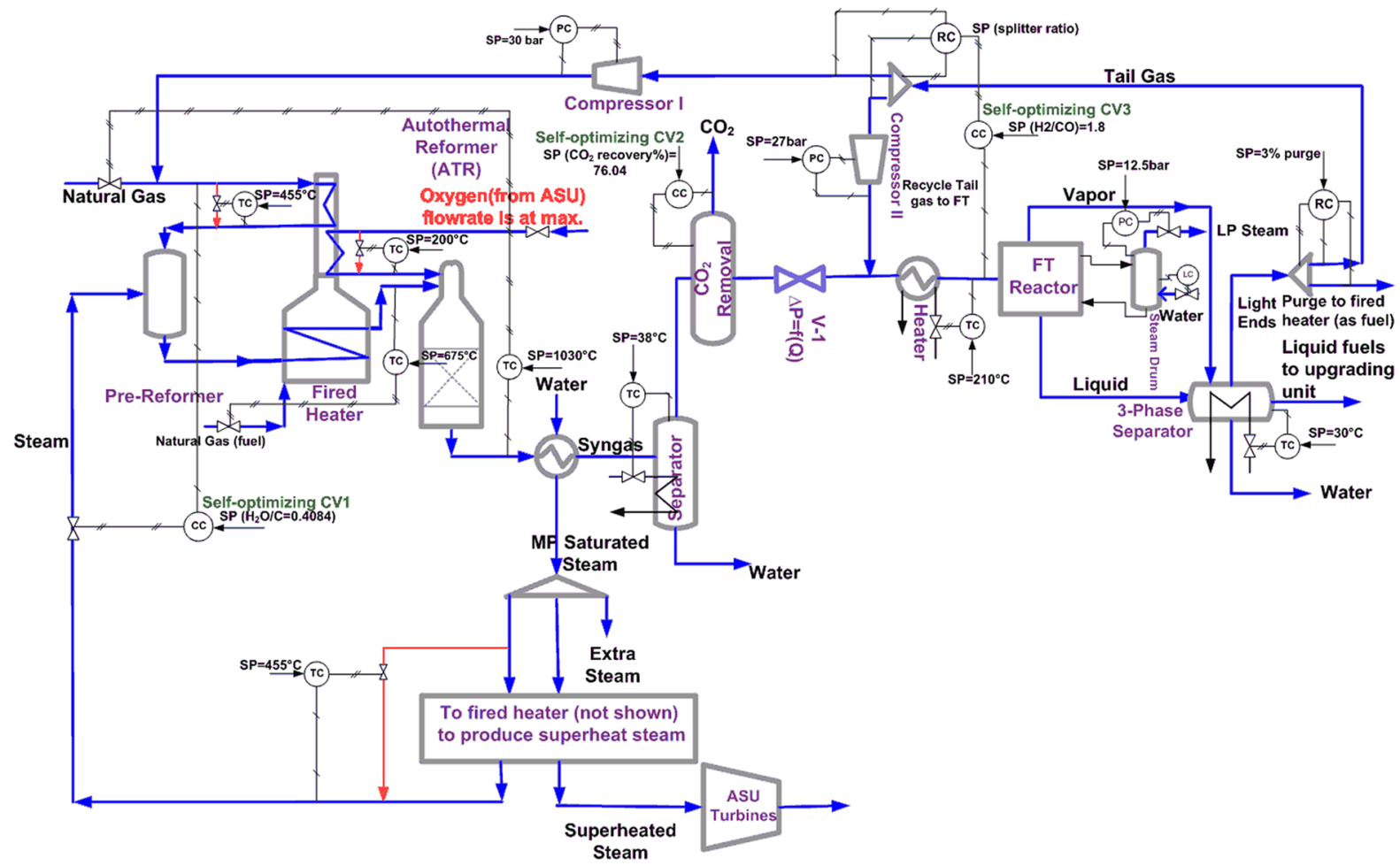

Figure 10. Possible control structure for mode II of operation.

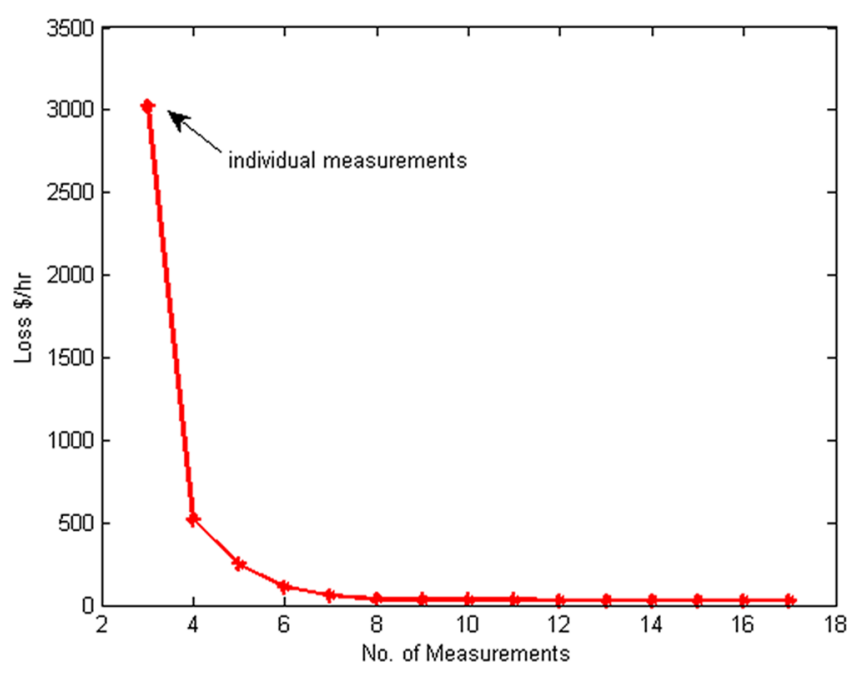

Figure 11. Minimum worst-case loss with different number of measurements (mode II).

Figure 9 shows that after saturation of oxygen capacity, as the feed natural gas feed rate increases, $\mathrm{CO}$ and $\mathrm{H}_{2}$ conversions decrease and the purge flow rate and the recycle increase, all because of the constant volume of the FT reactor. This is similar to the snowballing effect, ${ }^{21}$ which should be avoided. Therefore, the FT reactor volume may be viewed as the bottleneck of the process. Actually, the bottleneck for operation is the active constraints, but in terms of redesign it may be better to increase the reactor volume.

Unconstrained CVs in Mode II (point B). In mode II, there are 16 DOFs because the natural gas feed rate gives one extra compared to mode I. At the optimal point (point B), there are four active constraints and the same nine equality constraints as in mode I. The extra active constraint compared to mode I is the maximum oxygen flow rate. Since it then cannot be used to control the ATR exit temperature (active constraint) as we did in mode I, we select to use the natural gas feed rate to control the ATR temperature. The other pairings for control of the constraints are as for mode I. We are then again left with three unconstrained degrees of freedom which are the same as in mode I: $\mathrm{H}_{2} \mathrm{O} / \mathrm{C}, \mathrm{CO}_{2}$ removal percent, and recycle ratio to FT. The self-optimizing analysis is repeated to find the best set of CVs. Compared to case I, we add the maximum oxygen flow rate as a disturbance $\left(d_{8}, 5 \%\right)$.

Individual Measurements. By applying the exact local method, we find the best individual measurements. The best five sets are presented in Table 8 . In mode II, two of the unconstrained degrees of freedom are found to be selfoptimizing CVs $\left(u_{1}=\mathrm{H}_{2} \mathrm{O} / \mathrm{C}\right.$ and $u_{2}=\mathrm{CO}_{2}$ removal $)$. The best third $\mathrm{CV}$ is the ratio $\mathrm{H}_{2} / \mathrm{CO}$ into the $\mathrm{FT}$ reactor, which should be paired with the only remaining degree of freedom, which is the recycle tail gas ratio $\left(u_{3}\right)$. The resulting control structure is shown in Figure 10. Note that the objective of this work is to select controlled variables (CVs) and the shown pairings with the manipulated variables (MVs) is only a suggestion. Final pairings need to be decided and validated by using dynamic simulation, which we will consider later as our future work. By comparing the best individual measurement sets for the two modes of operation we find one common set, which is the third set in Tables 4 and 8 , and interestingly, we see that two measurements, $y_{3}\left(\mathrm{CO}_{2}\right.$ removal $)$ and $y_{5}\left(\mathrm{H}_{2} / \mathrm{CO}\right.$ in fresh syngas), have almost the same set point values (see the optimal values in Table 7). The set point of the third measurement, $\mathrm{H}_{2} \mathrm{O}$ / $\mathrm{C}$, changes from 0.6010 in the nominal case to 0.4084 in the optimal throughput case (point B).

In the "snowballing" region between operating points $\mathrm{A}$ and $\mathrm{B}$, one can view the $\mathrm{H}_{2} \mathrm{O} / \mathrm{C}$ set point as throughput manipulator (TPM). As mentioned, from a practical point of view, it may be better to operate the plant closer to point A. This may be 
Table 9. Best Set of Combination Measurements and Their Corresponding Losses in Comparison with the Best Individual Measurements Set (Mode II)

\begin{tabular}{|c|c|c|}
\hline no. measurements & best set of combinatorial CVs & $\min$ worst-case loss (USD/h) \\
\hline 3 & $\begin{array}{l}\mathrm{CV} 1=y_{2} \\
\mathrm{CV} 2=y_{3} \\
\mathrm{CV} 3=y_{7}\end{array}$ & 3,022 \\
\hline 4 & $\begin{array}{l}\mathrm{CV} 1=1.2265 y_{2}-3.9023 y_{6}+26.5645 y_{11}-44.1699 y_{12} \\
\mathrm{CV} 2=-1.4168 y_{2}-3.8972 y_{6}+27.4781 y_{11}-43.8481 y_{12} \\
\mathrm{CV} 3=-0.1675 y_{2}+6.5306 y_{6}-44.4148 y_{11}+63.5875 y_{12}\end{array}$ & 520 \\
\hline 5 & $\begin{array}{l}\mathrm{CV} 1=-3.2704 y_{6}-11.0752 y_{10}+23.9689 y_{11}-39.4867 y_{12}+0.0001 y_{17} \\
\mathrm{CV} 2=-5.6662 y_{6}+9.1168 y_{10}+37.8373 y_{11}-59.4219 y_{12}-0.0002 y_{17} \\
\mathrm{CV} 3=6.1857 y_{6}+0.5967 y_{10}-42.2267 y_{11}+60.4177 y_{12}-0.0000 y_{17}\end{array}$ & 153 \\
\hline 6 & $\begin{aligned} \mathrm{CV} 1= & -1.5199 y_{6}-2.5054 y_{7}-10.0711 y_{10}+18.6901 y_{11}-44.9909 y_{12} \\
& +14.1532 y_{15}\end{aligned}$ & 112 \\
\hline & $\begin{aligned} \mathrm{CV} 2= & -14.6808 y_{6}+15.4651 y_{7}+0.8535 y_{10}+46.1202 y_{11}-11.2275 y_{12} \\
& -66.6206 y_{15} \\
\text { CV3 }= & 4.9366 y_{6}+2.0426 y_{7}-0.4327 y_{10}-40.3465 y_{11}+66.3164 y_{12} \\
& -9.4631 y_{15}\end{aligned}$ & \\
\hline 7 & $\begin{aligned} \mathrm{CV} 1= & 4.3020 y_{2}+0.7874 y_{3}-3.1178 y_{6}+1.4389 y_{7}+12.1582 y_{11} \\
& -12.3659 y_{12}-13.6128 y_{15}\end{aligned}$ & 61 \\
\hline & $\begin{aligned} \mathrm{CV} 2= & 0.7497 y_{2}+0.2475 y_{3}-13.2986 y_{6}+14.2588 y_{7}+39.8464 y_{11} \\
& -5.0080 y_{12}-63.7779 y_{15}\end{aligned}$ & \\
\hline & $\begin{aligned} \mathrm{CV} 3= & 0.0725 y_{2}+0.0196 y_{3}+5.3032 y_{6}+1.5697 y_{7}-41.2960 y_{11} \\
& +66.0941 y_{12}-7.6749 y_{15}\end{aligned}$ & \\
\hline
\end{tabular}

achieved from increasing the set point for $\mathrm{H}_{2} \mathrm{O} / \mathrm{C}$ from 0.4084 (point B) to 0.5357 (point A).

Measurement Combinations as CVs. As an alternative to individual measurements, we consider also combinations of $\mathrm{CVs}$ in mode II. Figure 11 and Table 9 illustrate the results. By combining four, five, six, and seven measurements, the worst-case loss decreases significantly to $520,153,112$, and $61 \mathrm{USD} / \mathrm{h}$, respectively.

\section{CONCLUSIONS}

The steady-state top-down part of the general plantwide control procedure was applied for selection of the best controlled variables (CVs) for a GTL process in two modes of operation. In mode I, the natural gas feed rate is given, and in mode II, the natural gas feed rate is a degree of freedom for optimization in order to achieve the maximum possible profit. The transition from mode I to mode II occurs when the oxygen flow rate reaches its maximum. In mode II, when the oxygen flow rate saturates (point A), the recycle flow rate to the FT reactor increases significantly as we further increase the feed rate toward the optimal point B. The purge flow and compressor II duty also increase. This snowballing effect should be avoided. In addition, the economic benefit of increasing the feed rate is small; therefore, it may be better in practice to operate closer toward point $\mathrm{A}$.

In both mode I and mode II of operation, we have three remaining unconstrained steady-state degrees of freedom, and among the best corresponding individual measurement CV sets, we found for both modes two CVs with almost the same set point value $\left(\mathrm{H}_{2} / \mathrm{CO}\right.$ in fresh syngas and $\mathrm{CO}_{2}$ removal percent $)$ and a third one $\left(\mathrm{H}_{2} \mathrm{O} / \mathrm{C}\right.$ feed $)$ where the set point decreases from 0.6010 (nominal case) to 0.4084 (optimal throughput, point B) and this choice gives a simple transition. In mode II, the set point of the steam to carbon feed ratio $\left(\mathrm{H}_{2} \mathrm{O} / \mathrm{C}\right)$ can be chosen as the throughput manipulator (TPM) in the "snowballing region" between points $A$ and $B$, and by reducing its value we can move closer to point $\mathrm{A}$, where snowballing is avoided.

Use of combinations of measurements reduces significantly the worst-case loss. In both modes, we reach almost zero loss by combining seven measurements.

\section{AUTHOR INFORMATION}

\section{Corresponding Author}

*Tel.: +47 73594154. Fax: +47 73594080. E-mail: skoge@ntnu. no.

\section{Notes}

The authors declare no competing financial interest.

\section{REFERENCES}

(1) GTL-Workshop. Introduction to GTL Technology, PreSymposium Workshop; Organized by Gas Processing Center and Shell Company Doha, Qatar, 2010.

(2) Panahi, M.; Rafiee, A.; Skogestad, S.; Hillestad, M. A Natural Gas to Liquids (GTL) Process Model for Optimal Operation. Ind. Eng. Chem. Res. 2012, 51 (1), 425-433.

(3) Skogestad, S. Control structure design for complete chemical plants. Comput. Chem. Eng. 2004, 28 (1-2), 219-234.

(4) Rostrup-Nielsen, J.; Dybkjaer, I.; Aasberg-Petersen, K. Synthesis gas for large scale Fischer-Tropsch synthesis. Prepr.-Am. Chem. Soc., Div. Pet. Chem. 2000, 45 (2), 186-189. 
(5) Schanke, D.; Sogge, J. Personal communication. Statoil, Research Center, Trondheim, Norway, 2010.

(6) Aasberg-Petersen, K.; Christensen, T. S.; Stub Nielsen, C.; Dybkjær, I. Recent developments in autothermal reforming and prereforming for synthesis gas production in GTL applications. Fuel Process. Technol. 2003, 83 (1-3), 253-261.

(7) Christensen, T. S. Adiabatic prereforming of hydrocarbons - - an important step in syngas production. Appl. Catal., A: Gen. 1996, 138 (2), 285-309.

(8) Aasberg-Petersen, K.; Bak Hansen, J. H.; Christensen, T. S.; Dybkjaer, I.; Christensen, P. S.; Stub Nielsen, C.; Winter Madsen, S. E. L.; Rostrup-Nielsen, J. R. Technologies for large-scale gas conversion. Appl. Catal., A: Gen. 2001, 221 (1-2), 379-387.

(9) Yates, I. C.; Satterfield, C. N. Intrinsic kinetics of the FischerTropsch synthesis on a cobalt catalyst. Energy Fuels 1991, 5 (1), 168173.

(10) Iglesia, E., Reyes, S. C.; Soled, S. L. Reaction-transport selectivity models and the design of Fischer-Tropsch catalysts. Computer-Aided Design of Catalysts; Becker, E. R., Pereira, C. J., Eds.; Marcel Dekker: New York, 1993; pp 199-257.

(11) Yermakova, A.; Anikeev, V. I. Thermodynamic Calculations in the Modeling of Multiphase Processes and Reactors. Ind. Eng. Chem. Res. 2000, 39 (5), 1453-1472.

(12) Song, H.-S.; Ramkrishna, D.; Trinh, S.; Wright, H. Operating strategies for Fischer-Tropsch reactors: A model-directed study. Korean J. Chem. Eng. 2004, 21 (2), 308-317.

(13) Bakkerud, P. K. Personal communication, 2009.

(14) Dybkjær, I.; Christensen, T. S.; Iglesia, J. J. S. E.; Fleisch, T. H. Syngas for large scale conversion of natural gas to liquid fuels. Stud. Surf. Sci. Catal. 2001, 136, 435-440.

(15) UniSim; UniSim Design Honeywell Co.; 2008; R380.

(16) Halvorsen, I. J.; Skogestad, S.; Morud, J. C.; Alstad, V. Optimal Selection of Controlled Variables. Ind. Eng. Chem. Res. 2003, 42 (14), 3273-3284.

(17) Kariwala, V.; Cao, Y.; Janardhanan, S. Local Self-Optimizing Control with Average Loss Minimization. Ind. Eng. Chem. Res. 2008, 47 (4), 1150-1158.

(18) Kariwala, V.; Cao, Y. Bidirectional branch and bound for controlled variable selection. Part II: Exact local method for selfoptimizing control. Comput. Chem. Eng. 2009, 33 (8), 1402-1412.

(19) Alstad, V.; Skogestad, S.; Hori, E. S. Optimal measurement combinations as controlled variables. J. Process Control 2009, 19 (1), $138-148$.

(20) Kariwala, V.; Cao, Y. Bidirectional Branch and Bound for Controlled Variable Selection Part III: Local Average Loss Minimization. IEEE Trans. Ind. Inf. 2010, 6 (1), 54-61.

(21) Luyben, W. L. Snowball effects in reactor/separator processes with recycle. Ind. Eng. Chem. Res. 1994, 33 (2), 299-305. 